\title{
Testosterone replacement in male hypogonadism
}

This article was published in the following Dove Press journal:

Clinical Pharmacology:Advances and Applications

9 September 2010

Number of times this article has been viewed

\section{Sanjay Kalra' \\ Navneet Agrawal ${ }^{2}$ \\ Satish Kumar ${ }^{3}$ \\ Amit Sharma'}

'Department of Endocrinology, Bharti Hospital, Karnal, India; ${ }^{2}$ Dept of Medicine, GR Medical College, Gwalior, India; ${ }^{3}$ Clinical Research, EXCEL Life Sciences, NOIDA, India
Correspondence: Sanjay Kalra Bharti Hospital, Kunjpura Road, Karnal, India I3200 I

Tel +9l 1842200004

Fax +9| 1842267885

Email bridekn!@gmail.com
Abstract: This article contains a review of the clinical aspects of testosterone replacement in androgen deficiency of the aging male.

Keywords: testosterone, supplementation, hypogonadism, ADAM

As men age, there is a gradual decline in testosterone of $1.0 \%$ and $1.2 \%$ (total and free levels, respectively), annually, after age 40 . Free testosterone levels decline faster because of the associated increase in sex hormone-binding globulin., ${ }^{1,2}$

This phenomenon is known as andropause, or as (partial) androgen deficiency of the aging male $[(\mathrm{P}) \mathrm{ADAM}]$, when it is associated with signs and symptoms of androgen deficiency. ${ }^{3}$

ADAM can be defined biochemically, or clinically. Biochemically, a total testosterone cut off of $325 \mathrm{ng} \%(11.3 \mathrm{nmol} / \mathrm{L})$ leads to a diagnosis of androgen deficiency in $20 \%$ of men $>60$ years, $30 \%$ of men $>70$ years, and $50 \%$ of men $>80$ years. ${ }^{4}$ Many of these men, however, have no clinical features of testosterone deficiency, and risk being overtreated.

The clinical approach utilizes symptoms and signs of androgen deficiency. These, however, are nonspecific, and may be due to other illnesses. Lethargy, asthenia, lack of concentration, disturbed sleep, irritability, and depression are the common symptoms which have multiple etiologies.

Both clinical and biochemical parameters, therefore, must be used to define ADAM, before it is treated.

\section{Symptoms and signs}

The signs and symptoms of androgen deficiency may be nonspecific. In general, the features can be classified as physical, psychological, and sexual symptoms and signs, and laboratory abnormalities. These are listed below:

\section{Physical symptoms/signs}

- decreased muscle bulk

- increased adiposity

- loss of secondary body hair

- loss of vigor 


\section{Psychological symptoms/signs}

- low mood

- poor cognition

- irritability

\section{Sexual symptoms/signs}

- declining sexual desire

- erectile dysfunction

\section{Laboratory abnormalities}

- loss of bone mineral density

- atherosclerosis

\section{Effects of treatment}

Physiologic androgen replacement can be differentiated from pharmacological androgen therapy. Physiologic androgen replacement, which is the focus of this review, aims to achieve normal androgen levels in serum and tissue, so that the signs and symptoms of androgen deficiency are alleviated in a hypogonadal male. It does not target a specific organ system, and does not try to reach supraphysiological levels. On the other hand, pharmacological androgen therapy, such as for anemia due to bone marrow failure, or for endometriosis, is aimed at producing specific effects on specific tissues.

A long term (3 years long) trial has demonstrated increase in lean mass, with reduction in fat mass in 96 men aged 73 years who wore a scrotal testosterone patch delivering $6 \mathrm{mg}$ testosterone every 24 hours. ${ }^{5,6}$

No change was noted in muscle strength and function, bone density, or subjective perception of energy or sexual functions with testosterone.

Though the prostatic specific antigen concentration increased slightly over the first six months, it remained stable for the remainder of the study. ${ }^{5}$ Urodynamic parameters and number of clinically significant prostate events were similar in the testosterone and placebo groups. Hemoglobin and hematocrit increased significantly in the testosterone group over the first 6 months.

Libido and sexual function improved with transdermal testosterone replacement in clear cut cases of hypogonadism. ${ }^{7}$

Other randomized, placebo controlled trials in older healthy men have shown beneficial effects of sublingual testosterone in functional performance, hand grip strength, lean body mass $(+3.8 \mathrm{~kg})$, bone mineral density at lumbar spine $(+10.2 \pm 1.4 \%)$, and hip $(+2.7 \pm 0.7 \%)$ at 36 months, along with a decrease in low density lipoprotein (LDL) cholesterol. $^{8}$
Simultaneous use of finasteride ${ }^{9}$ in one study was shown to reduce the increase in prostate volume seen with exogenous testosterone in hypogonadal men. Testosterone replacement, either injectable or noninjectable, in elderly men leads to only modest or no decrease in plasma HDL. ${ }^{10-12}$ The levels of LDL are inversely proportional to testosterone concentration. ${ }^{13,14}$

Testosterone supplementation of middle aged men reduces visceral fat, serum glucose, blood pressure, and improves insulin sensitivity. ${ }^{15,16}$ One trial with oral testosterone has shown reduction in symptoms of angina in men with coronary heart disease. ${ }^{17} \mathrm{~A}$ recent study, however, has been stopped prematurely ${ }^{18}$ because of excess cardiovascular events noted in the testosterone gel-treated arm of a study involving elderly community-dwelling men (mean age 73 years) with low testosterone levels.

Studies have shown improved spatial and verbal memory with supraphysiological testosterone levels, ${ }^{19}$ and improved spatial and working memory with high normal levels in healthy older men. ${ }^{20}$

Results related to major depression have been conflicting, with one study suggesting a benefit, ${ }^{21}$ but another reporting no effect of supraphysiological testosterone therapy in this condition. $^{22}$

\section{To treat or not to treat}

Treatment should be decided based on both clinical and biochemical parameters. ${ }^{23}$ Biochemical confirmation is carried out if patients present with signs and symptoms suggestive of androgen deficiency. Diagnosis should not be made during an acute or subacute illness.

An arbitrary cut off of $200 \mathrm{mg} \%(7.0 \mathrm{nmol} / \mathrm{L})$ has been suggested. ${ }^{24,25}$ This cut off is lower than that suggested by earlier population-based studies. ${ }^{4}$ The discrepancy may be a reflection of the greater understanding of need for optimal androgen levels by endocrinologists.

The clinical features which demonstrate highest association with low testosterone levels are decreased morning erections, decreased sexual desire, erectile dysfunction, and low physical activity. ${ }^{26}$ Physical and sexual symptoms are likely to provide more specificity than psychological symptoms. ${ }^{26}$

Laboratory evaluation is ideally carried out by measuring early morning total or free testosterone levels. One should be aware that total testosterone can be affected by changes in sex hormone binding globulin (SHBG) concentration. SHBG concentrations are reduced in obesity, nephrotic syndrome, hypothyroidism, and use of glucocorticoids, 
progestins, and androgenic steroids. ${ }^{27}$ SHBG cause increases in aging, cirrhosis, hyperthyroidism, HIV infection, and estrogen use.

The aim of treatment is to return testosterone value to 'physiologic' age-matched levels. Titration of dose is carried out according to serum testosterone levels.

The duration of testosterone therapy is uncertain, and may depend on changes in prostate size, PSA levels, and hematocrit.

\section{Choosing a testosterone preparation}

Various testosterone preparations are available for use. ${ }^{3}$

Oral testosterone undecanoate, formulated in oleic acid, is absorbed through the lymphatics into systemic circulation, bypassing the liver. Doses of 40 to $80 \mathrm{mg}$ two to three times a day with meals are used, but clinically responses are variable.

Oral testosterone should be used initially for all patients requiring androgen replacement, because it has the advantage of being easy to discontinue in case of an adverse clinical reaction.

Injectable and transdermal preparations are also available. Esterification of testosterone at the 17- $\beta$ hydroxyl position makes it hydrophobic and increase the duration of action, in a manner directly proportional to the length of the side chain.

Testosterone undecanoate ${ }^{28}$ has the longest duration of action, and is injected in a dose of $1,000 \mathrm{mg}$, followed by a similar dose at 6 weeks, and then every 12 weeks. Stable levels of testosterone are achieved, but the large volume $(4 \mathrm{~mL})$ may cause some discomfort. Dose titration can be done by varying the dose (1-4 mL) or frequency ( 6 to 8 to 12 weekly) of injections.

A mixture of testosterone enanthate, cypionate, and propionate is also available as a total dose of $100 \mathrm{mg}$ and $250 \mathrm{mg}$, to be administered IM every 14 to 21 days. It is easy to use, and is effective, but leads to peaks or supraphysiological concentrations, and lows or hypogonadal ranges of testosterone, during the mid-phase and late phase of the dosing interval.

Transdermal preparations are available for nongenital use and scrotal use as well. The gel is applied in a dose of 5 to $20 \mathrm{~g}$ on scrotal skin, and it achieves uniform concentrations over 24 hours. It is easy to use, invisible, and allows for flexibility of dosing, but can be transferred through skin to skin contact.
Nongenital $5 \mathrm{mg}$ patches also available. Controlled release, bioadhesive $30 \mathrm{mg}$ testosterone tablets can be applied every 24 hours to the buccal mucosa. Implant of crystalline testosterone can be inserted into the subcutaneous tissue, and maintain adequate serum testosterone levels for up to 6 months, if used in a dose of 4 to $6200 \mathrm{mg}$ implants.

Oral 17- $\alpha$ alkylated testosterone derivatives are no longer used, because of potential hepatotoxicity.

Choice of the testosterone preparation depends on various factors. In general, injectable preparations are more economical than others. Oral and transdermal preparations are easier to administer, while some patients prefer the occasional injectable therapy. Oral testosterone has a quicker onset and shorter duration of action, while transdermal testosterone leads to less increase in PSA than oral preparations. ${ }^{29}$

\section{Contraindications}

The contraindications to testosterone therapy are listed below:

1. Metastatic prostate cancer

2. Breast cancer

3. Undiagnosed prostate nodule or induration

4. Unexplained PSA elevation $>3 \mathrm{ng} / \mathrm{mL}$

5. Erythrocytosis (hematocrit $>50 \%$ )

6. Severe BPH symptoms (AUA/IPSS >19)

7. Unstable severe congestive heart failure (class III or IV)

\section{Adverse events}

Testosterone-related adverse events are usually uncommon. However, frequently seen side effects include acne, oily skin, breast tenderness, erythropoiesis, detection of subclinical prostate cancer, increase in prostate volume, and growth of metastatic prostate cancer. None of the randomized clinical trials on testosterone has been powered for long-term prostate safety. Most studies, however, have shown no change in prostate size or urine flow prostate symptom score with testosterone. $^{30}$

There is only weak evidence of an association of testosterone replacement with gynaecomastia, male pattern baldness, worsening of BPH symptoms, growth of breast cancer, and induction or worsening of obstructive sleep apnea. ${ }^{3}$

\section{Monitoring of testosterone therapy}

Men should be followed up for 3 months after starting therapy, and annually thereafter. The aim should be to maintain serum testosterone levels in the mid normal range. Serum LH and FSH are not used to monitor therapy. ${ }^{9}$ 
Hemoglobin, hematocrit, digital prostate examinations, and PSA should be checked regularly.

Patients on injectable testosterone mixtures should have their testosterone levels assessed midway between injections, aiming for a level $350-700 \mathrm{ng} / \mathrm{mL}$. Those on the injectable testosterone undecanoate should have a serum testosterone assessment prior to the injection. Levels should be assessed 3 to 12 hours after applying transdermal patch, 3 to 5 hours after ingesting oral testosterone undecanoate, at any time while on a testosterone gel, and just prior to inserting a buccal tablet.

Hematocrit should be checked at baseline, at 3 months, then annually. Testosterone should be stopped if hematocrit rises to $>54 \%$ and reinitiated slowly when it falls to below $50 \%$.

Digital rectal examination and PSA should be carried out at baseline, at 3 months, and then as clinically indicated. ${ }^{9}$

A urology consultation should be sought if serum PSA rises above $4.0 \mathrm{ng} / \mathrm{mL}$, increases by $1.4 \mathrm{ng} / \mathrm{mL}$ or more over 12 months, or $>0.4 \mathrm{ng} / \mathrm{mL} /$ year for 2 years. A urology consultation is also indicated if a prostate abnormality is noted or the AUA/IPSS symptoms score rises above 19.

\section{Conclusion}

Testosterone replacement is an effective method of treating hypogonadism in elder men, if used judiciously. An understanding of possible benefits and risks, judicious choice of the testosterone preparation, combined with regular monitoring, makes testosterone replacement a beneficial choice for older men with both biochemical and clinical evidence of androgen deficiency. Both physicians and patients must be aware of the possible side effects and complications of testosterone therapy.

\section{Disclosure}

The authors report no conflicts of interest in the work.

\section{References}

1. Vermeulen A. Clinical review 24: androgen in aging male. $J$ Clin Endocrinol Metab. 1991;73(2):221.

2. Tenover JS. Androgen administration to aging men. Endocrinol Metab Clin North Am. 1994;23:877.

3. Lambert SWJ. Endocrinology and aging, In: Kronenberg HM, Helmed S, Polonsky KS, Larsen PR, eds. Williams Textbook of Endocrinology. Saunders Elsevier, Philadelphia, 2008: pp. 1185-1202.

4. Harman SM, Melter EJ, Tobin JD, et al. Longitudinal effects of aging on serum total and free testosterone levels in healthy men. Baltimore Longitudinal Study of Aging. J Clin Endocrinol Metab. 2001;86: 724-731.

5. Snyder PJ, Peachey H, Hannoush P, et al. Effect of testosterone treatment on bone mineral density in men over 65 years of age. J Clin Endocrinol Metab. 1999;84(6):1966.
6. Snyder PJ, Peachey H, Hannoush P, et al. Effect of testosterone treatment on body composition and muscle strength in men over 65 years of age. J Clin Endocrinol Metab. 1999;84(8):2647.

7. Wang C, Swedloff RS, Iranmanesh A, et al. Transdermal testosterone gel improves sexual function, mood, muscle strength, and body composition parameters in hypogonadal men. Testosterone Gel Study Group. J Clin Endocrinol Metab. 2000;85(8):2839.

8. Wang C, Eyre DR, Clarc R, et al. Sublingual testosterone replacement improves muscle mass and strength, decrease bone resorption, and increase bone formation markers in hypogonadal men- a clinical research center study. J Clin Endocrinol Metab. 1996;81(10):3654.

9. Amory JK, Watts NB, Easley KA, et al. Exogenous testosterone or testosterone with finasteride increase bone mineral density in older men with low serum testosterone. J Clin Endocrinol Metab. 2004;89(2):503.

10. Bhasin S, Cunningham GR, Hayes FJ, et al. Testosterone therapy in adult men with androgen deficiency syndromes: an endocrine society clinical practice guideline. J Clin Endocrinol Metab. 2006;91:1995-2010.

11. Sih R, Morley JE, Kaiser FE, et al. Testosterone replacement in older hypogonadal men: a 12-month randomized controlled trial. J Clin Endocrinol Metab. 1997;82:1661-1667.

12. Synder PJ, Peachey H, Berlin JA, et al. Effect of transdermal testosterone treatment on serum lipid and apolipoprotein levels in men more that 65 years of age. Am J Med. 2001;111:255-260.

13. Chaw KT, Barrett-Conner E. Lower endogenous androgens predict central adiposity in men. Ann Epidemiol. 1992;2:675-682.

14. Seidell JC, Bjorntorp P, Sjostorm L, et al. Visceral fat accumulation in men is positively associated with insulin, glucose and C-peptide levels, but negatively with testosterone levels. Metabolism. 1990;39: 897-901.

15. Martin P, Holmang S, Jonsson L, et al. The effect of testosterone treatment on body composition and metabolism in middle-aged obese men. Int J Obes Relat Metab Disord. 1992;16:991-997.

16. Marin P, Krotkiewski M, Bjorntorp P. Androgen treatment of middle-aged, obese men: effects on metabolism, muscle and adipose tissue. Eur J Med. 1992;1:329-336.

17. English KM, Steeds RP, Jones TH, et al. Low dose transdermal testosterone therapy improves angina threshold in men with chronic stable angina: a randomized, double blind, placebo controlled study. Circulation. 2000;102:1906-1911.

18. Basaria S, Coviello AD, Travison TG, et al. Adverse events associated with testosterone administration. $N$ Engl J Med. 2010 [Epub ahead of print].

19. Cherrier MM, Asthana S, Plymate S, et al. Testosterone supplementation improves spatial and verbal memory in healthy older men. Neurology. 2001;57:80-88.

20. Janowsky JS, Chavez B, Orwoll E. Sex steroids modify working memory. J Cogn Neurosci. 2000;12:407-414.

21. Pope HG Jr, Cohane GH, Kanayama G, et al. Testosterone gel supplementation for men with refractory depression: a randomized, placebo-controlled trial. Am J Psychiatry. 2003;160:105-111.

22. Seidman SN, Spatz E, Rizzo C, et al. Testosterone replacement therapy for hypogonadal men with major depressive disorder: A randomized, placebo-controlled clinical trial. J Clin Psychiatry. 2001;62:406-412.

23. Liu PY, Swerdloff RS, Veldhuis JD. Clinical review 171: the rationale, efficacy and safety of androgen therapy in older men: future research and current practice recommendations. J Clin Endocrinol Metab. 2004;89(10):4789.

24. Bhasin S, Bremner WJ. Clinical review 85: emerging issues in androgen replacement therapy. J Clin Endocrinol Metab. 1997;82(1):3.

25. Bhasin S, Bagatell CJ, Bremner WJ, et al. Issues in testosterone replacement in older men. J Clin Endocrinol Metab. 1998;83(10):3435.

26. Arnott JM, Wu FCW, Pye S, et al. A clinically relevant approach to defining the prevalence of late onset Hypogonadism in men from the general population. Presented at the 88th Endocrine Society Meeting, Boston, 2006 Jun 20-24. 
27. Rosner W. Sex steroids and the free hormone hypothesis. Cell. 2006;124:455-456; author reply 456-457.

28. Yassin AA, Haffejee M. Testosterone depot injection in male hypogonadism: a critical appraisal. Clin Interventions Aging. 2007;2(4):577-590.

29. Meikle AW, Arver S, Dobs AS, et al. Prostate size in hypogonadal men treated with a non-scrotal permeation-enhanced testosterone transdermal system. Urology. 1997;49:191-196.
30. Allan CA, McLachlan RI. Androgen deficiency disorder. In LJ Groot, JL Jameson, editors. Endocrinology, Elsevier, Philadelphia, 2006; 3159-3191.

\section{Publish your work in this journal}

Clinical Pharmacology: Advances and Applications is an international, peer-reviewed, open access journal publishing original research, reports, reviews and commentaries on all areas of drug experience in humans. The manuscript management system is completely online and includes a very quick and fair peer-review system, which is all easy to use.
Visit http://www.dovepress.com/testimonials.php to read real quotes from published authors. 